http://sciforum.net/conference/ece-1

Conference Proceedings Paper - Energies ,, Whither Energy Conversion? Present Trends, Current Problems and Realistic Future Solutions"

\title{
Strategic Analysis Adaptation Assessment: An Alternative to the Economic Storyline Scenario
}

\section{Susan Krumdieck ${ }^{1 *}$}

1 Department of Mechanical Engineering, University of Canterbury, Christchurch, New Zealand;

* Author to whom correspondence should be addressed

E-Mail: susan.krumdieck@ canterbury.ac.nz; Tel.: +64 3364 2987; Fax: +64 33642078

Received: 17 January 2014 / Accepted: 13 March 2014 / Published: 14 March 2014

\begin{abstract}
Scenarios of future trends are widely used by government and international agencies to inform decision-making. Story line scenarios usually assume a continued growth in energy demand projected from historical trends. If the future energy resource or related resource such as water or rare-earth minerals are constrained, then the story line scenario is not effective at informing engineering research, innovation and design. Story line scenarios also add very little to the understanding of sustainability, as the underlying assumption of continued demand growth is inherently unsustainable. This paper presents a strategic analysis approach to complex systems, which relies on identification of risks to energy systems, important activities and wellbeing. The risk information is used to frame a forward operating environment. This method mimics the actual processes of anthropogenic continuity, where people explore, experiment, learn from success and mistakes, and adapt to new circumstances. The method is applied to the case study of transportation fuel supply in New Zealand. Directions for immediate strategic engineering research and innovation are clear outcomes of the analysis.
\end{abstract}

Keywords: Sustainable Development; Strategic Analysis; Transportation, Scenarios 


\section{Introduction}

More than 20 years have passed since the publication of "Our Common Future" by the World Commission on Environment and Development in 1987, where the concept of sustainable development was formally stated (UN, 1987). However, a functional definition of sustainable development which directs behavior informs decision making and drives innovation is still illusive. In fact, the Bruntland Report was more aimed at achieving growth and development in poor countries than it was about curbing consumption in developed countries to ensure sustainabiltiy. Even as scientific documentation of biodiversity destruction, resource depletion and climate disruption are becoming more alarming, there is still no established practice of sustainable development and no procedure to define limits to growth (Meadows at el. 2004).

There are many different groups who develop scenarios of various systems using a wide range of modelling approaches (Energy Shift Project, 2014). Scenarios for small companies or the governments of smaller countries are often constructed from historical data, and past trends projected to forecast future trends. Future energy scenarios have been developed by a wide range of industry groups, government agencies, and researchers (Canyurt and Ozturk, 2006; Moffatt, 2004; Yamaguchi, 2004). Scenarios are commonly based on assumptions of economic growth, and at the time of writing, we have not been able to identify a standard, recognized method for constructing energy scenarios. In fact, the Energy Shift Project seminar in 2014 was a gathering of energy scneario experts with the objective of exploring scenario methodologies. The results of many current energy scenarios represent future situations which would be environmentally disastrous or physically impossible, mostly because the business as usual (BAU) or baseline scenario assumes continues growth of fossil fuel use into the indefinite future (IEA, 2013).

Tisdell (2004) has argued that economics is but one of many bottom lines for sustainable development. We propose that basing projections about the behavior of an energy supply system on economic assumptions doesn't provide any relevant information for the engineers who will play the major role in developing future energy systems. The study of economic activity is a study of human behavior in a specific context which includes effects of current prices, culture, availability of certain products or technologies, and functionality of certain systems. As an example, consider the very common statement in energy policy discussions in relation to a carbon tax: "as the price of fossil fuels increases, alternatives become more competitive." The only thing we know for sure if fossil fuels become more expensive is that fuel becomes more expensive. In general, having choices between two increasingly scarce and expensive options causes shifts in behaviors and choices that reduce the use of increasingly expensive resources. The most important thing to consider regarding scenarios about the future is that they are loaded naratives or frames of reference in which we try to make sense of information that explicity indicates change is inevitable. 
Energy issues are interconnected with economy, society and environment (Bassi, 2006). Many of these elements are often difficult to quantify and thus to build into a predictive dynamic model. Multi-criteria decision making (MCDM) techniques emerged to address quantifiable and unquantifiable issues. MCDM is gaining popularity in energy management and planning with sustainability goals. A range of criteria can be included in the social and environemntal areas as well as economic cost-benefit. A comprehensive review of various MCDM techniques has been conducted by Pohekar and Ramchandran (2004).

SWOT (strengths, weaknesses, opportunities and threats) is a recent development in regional planning is. SWOT was originally devised for corporate decision makers and has several examples of successful application (Terrados et al., 2007). SWOT is not widely reported as a sustainable development approach and has particular limitations of not providing analysis or a robust plan for engineering projects (Pickton and Wright, 1998).

\section{Strategic Analysis of Complex Systems}

A complex energy system is taken to include the technical system, but also the interactions of energy policy, economics, energy return on energy invested (EROI), carrying capacities and resource scarcity, consumer behavior, and relative importance of end uses for providing wellbeing (Krumdieck, 2013). Strategic analysis starts with building a picture of the historical context for changes in the system. By looking at past situations, we can illuminate biases in current assumptions about the importance of different energy end use behaviors and elasticities. For example, identification of risks to important activities and wellbeing. The relatively simple method offers a much more realistic approach to issue identification and action inanition for risk mitigation than is offered by the usual economic-based energy demand scenario. The outcome of a strategic analysis project is an action strategy which is one of the shortcomings of the SWOT exercise. The SA approach is described in the following section, followed by an example of the method results for the private motor transportation system in New Zealand.

As with all other system analysis methods, the SA method requires that a particular system be defined, as well as the context and surroundings in which the system operates. The SA method seeks to identify actions that should be taken at the present time in order to meet strategic energy/environment goals. This is accomplished by undertaking two projects and a prioritization analysis as illustrated in the flow chart in Figure 1. 
Figure 1. Flow chart diagram of the projects and analysis involved in developing the forward operating environment and identify path-break concepts for energy change strategy.

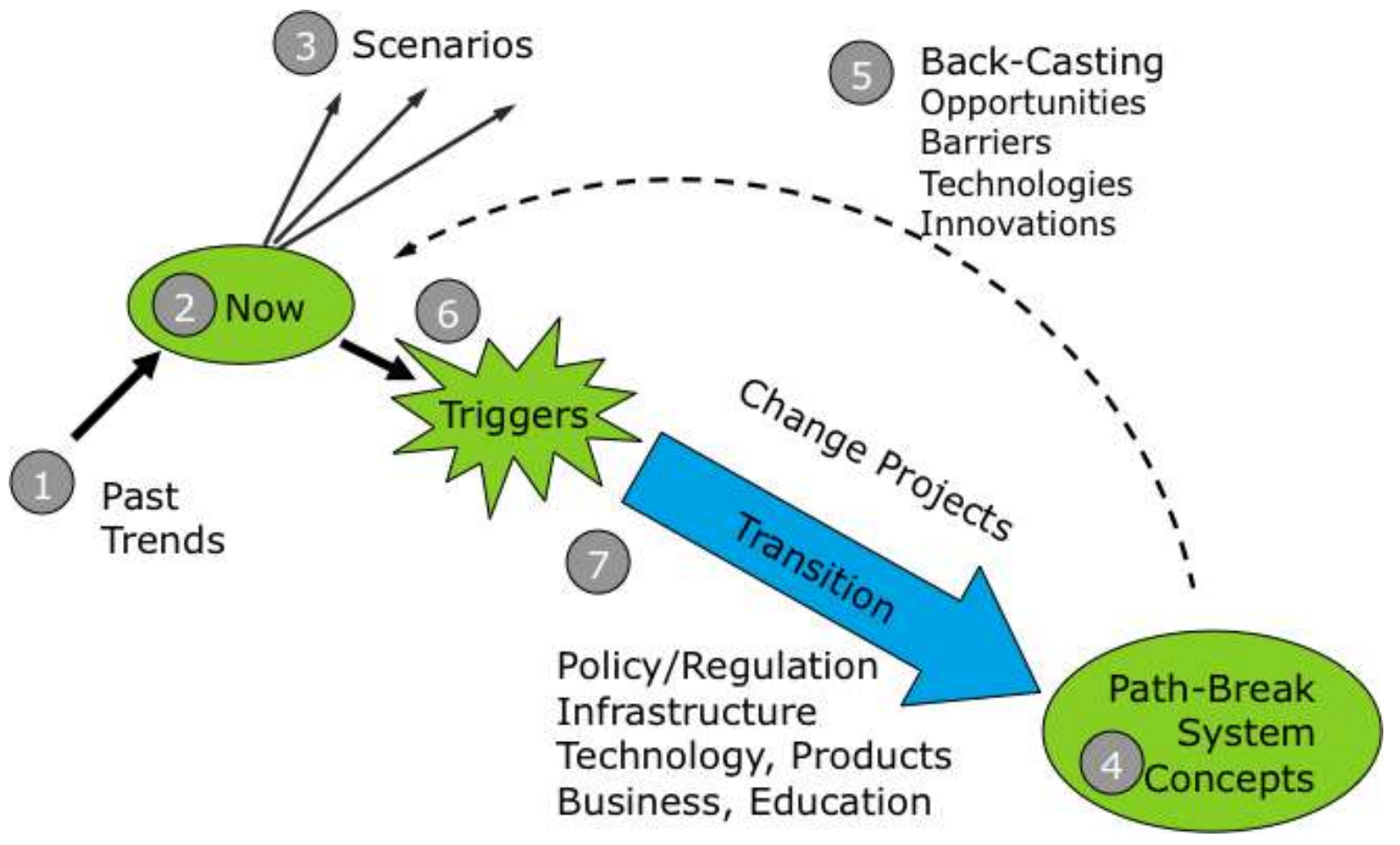

\subsection{Define the system and study past system dynamics}

An activity system is the target for strategic adaptation analysis. Characterization includes the energy supply, technology and infrastructure, people who use it, economy which allocates the resources, regulations which govern the activities, and the environment impacted by the activities. Past trends can be investigated by compiling data and fitting a curve. But the strategic approach looks more at relating the events and context of the time in history to the observed dynamics. For example, the historical exponential growth in demand for oil in the USA must be considered in the context of the low proportion of household costs represented by transportation, the elimination of most alternatives, construction of automobile dependent urban forms, and the media treatment of driving and cars. The $15 \%$ decline in oil demand in the USA in 1974-1979 should also be considered, to understand the adaptive capacity to reduced supply.

\subsection{Current energy, environment, economic and social context}

Current data on energy use, effects of energy policy and energy costs can be gathered in most countries for most activity systems. There are some important exceptions where data is scarce like freight transport between regions, supply chains, and goods movements within urban areas. Geographic information system (GIS) data, census data and travel surveys are rich sources of data about important eneryg activity systems. Most future scenarios and the strategic analysis method will typically use percentage changes from current levels of activity 
as the metric for investigation, so clarifying current activity levels and consumption levels is important.

\subsection{Future Scenarios}

The background in Section 1 gave descriptions of some of the more common approaches to storyline scenarios. A set of assumptions about future policy or technology change are imposed on a business as usual (BAU) continuation of historical demand trends. The most common idea in all scenario exercises is the idea of BAU. The most important assumption in constructing a BAU trajectory is that demand is exogenous to the energy system dynamics. In other words, it is usually assumed that supply grows to meet an ever growing demand. It is questionable if this has indeed been the historical pattern for energy. It makes sense that the boom in home building after World War II caused a demand for wood which was met by increased logging and milling of trees. But how does a demand for electricity supply exist before the electricity generation and distribution grid is built? How does the demand for oil grow before the availability of low cost fuel at widespread filling stations to fuel private vehicles purchased on credit? With energy, it should be considered that demand is in fact endogenous - that is it grows in response to availability and affordability. Clearly, demand declined dramatically in response to the OPEC oil embargo. The most recent petroleum fuel data also shows flat demand for gasoline and declining demand for personal vehicle travel.

\subsection{Strategic Analysis to generate path break concepts}

The fundamental assumption in the strategic analysis approach is that demand adapts to supply. Thus, the important energy supply for the activity system under study needs to be studied for the time-frame of the strategic analysis. The strategic approach to future energy resource availabiltiy is to estimate the probablity of future supply using expert and published data. Figure 2 shows a probability map of the future world oil supply (Krumdieck, 2014). The probability that a given supply level will be available in the year of interest was calculated by Monte Carlo simulation using the forward supply estimates from a metaanalysis of published petroleum geology studies. The cumulative probability range forms the forward operating environment, or the range of possibility. Most energy scenarios at this point may acknowledge a future decline in the supply of a current resource, like oil, but they will then apply a wedge between the BAU trendline and the energy supply trendline and postulate that new discoveries, improved efficiency or development of alternatives will fill the gap. 
Figure 2. The probability of future world oil supply from meta-analysis of petroleum geology publications.

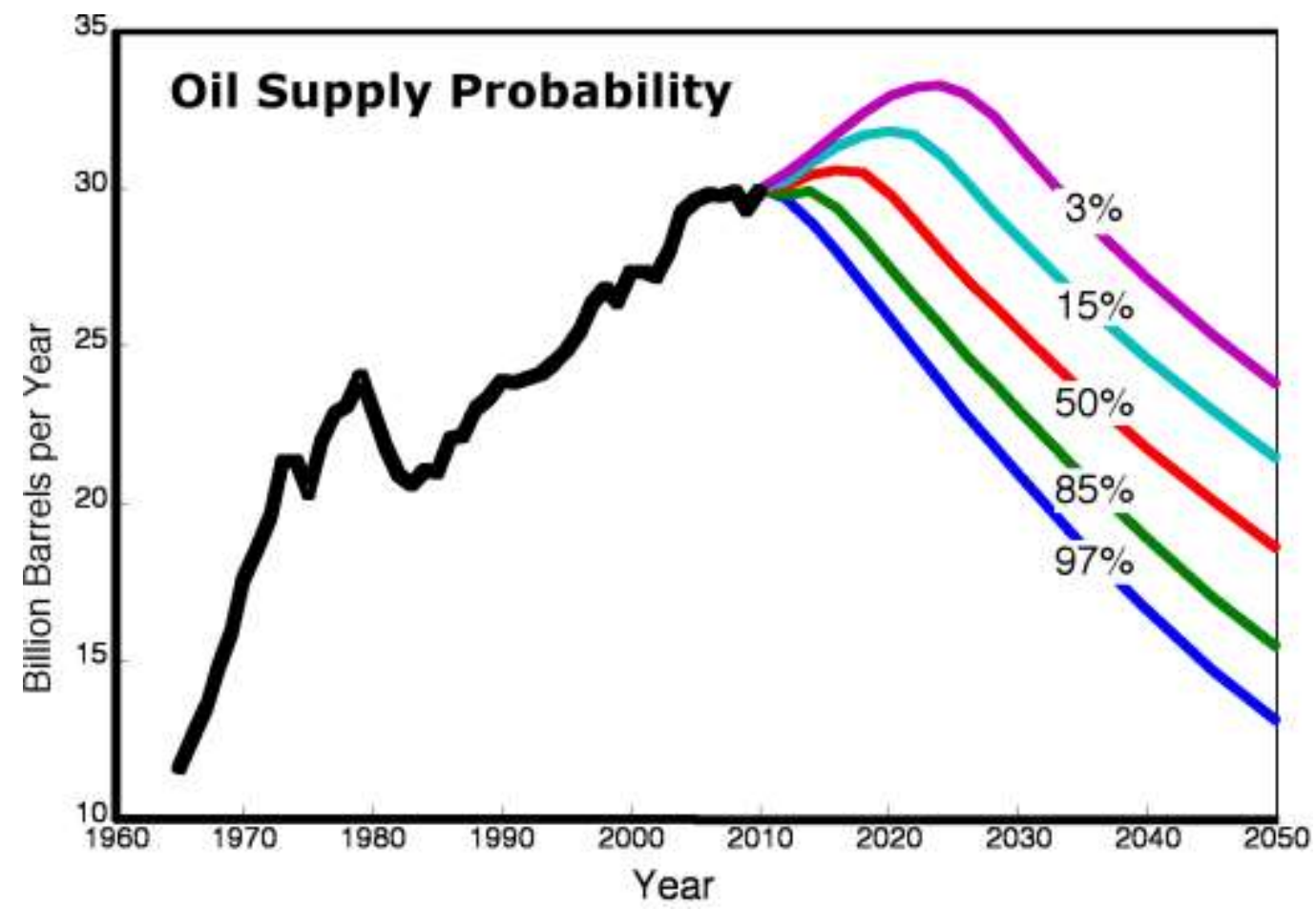

A strategy is a plan to operate to meet objectives given the circumstances, issues and risks. When the energy supply declines, demand declines and the stratgey is about adaptation. The adaptive capacity of the activity system under investigation is the ability to change energy usage to fit the operating environment while managing issues which could cause the system to fail.

A transformation concept is generated for the activity system at a particular position in the future. This is a very creative project that must include technical and economic feasibility. A systems engineering team will develop a "design space" model system that could satisfy the system requirements, needs and desires, that could be economically realized, and that is technically feasible. The primary objective of this concept generation mission is that the concept system must have minimal exposure to the risks which face the current system. It is NOT important that the transformation concept system be politically acceptable or even commercially desirable at the current point in time. The idea of the transformation concept is similar to the isentropic system model used in mechanical engineering. An isentropic system is basically a perpetual motion machine; it has no friction, no imperfections, and is $100 \%$ efficient. We're not being ignorant by modelling impossibly perfect systems, we actually learn a great deal about the design and performance of real systems by modelling impossibly perfect systems. 


\subsection{Backcasting Analysis for risk remediation}

Backcasting is a well-known process of considering the difference between a strategic goal and the current situation. The only precaution to offer here is that back casting in a strategic sense is not about trying to think of ways to preserve the BAU path. Rather backcasting would be aimed at identifying operational elements of the current system that reduce adaptive capacity or could hinder change of direction dictated by the forward operating environment.

\subsection{Trigger events}

Given that the BAU path represented by the storyline scenario is not actually possible, there will be a shift in demand and supply of energy and the associated changes in the activity system at some point. We may well anticipte that this shift would be precipitated by some dramatic event. In fact, in the case study of oil, the trigger event appears to have already occurred with the inflection of the supply from growth to plateau in 2006 and the severe price shock over 2007-2008. There may be multiple triggers to change, for example when the world oil supply passes another inflection and begins permanent decline some time around 2016 (Bureau of Infrasturucture, 2009).

\subsection{Transition development analysis}

The transition development analysis process is based on proposing possible risk remediation actions, then determining feasibility and the effectiveness for managing the identified risks. The adaptation risks were previously identified, and the transition concept is used as a benchmark for the effectiveness of the remediation actions being explored. The outcome of the analysis is a prioritized set of actions and projects which form an adaptation and transformation strategy which can develop within the forward operating environment for the particular system. The strategy may involve research in areas where the mitigation measures are not yet developed. The strategy may consist of specific technologies, or of certain policies that would mitigate the risks.

This process mimics the real process of exploration, research, learning, and trial and error that takes place as human societies adapt and evolve. Changes in the way people behave and in the infrastructure and technology they use are made in response to problems or to new opportunities. Once new technologies enter the market, they increase in efficiency through continuous research and improvement. The exception to this process is when there are no resource constraints apparent to the people in the society. In this latter case, increasingly higher consumptive development may continue until environmental systems are exhausted, and the system collapses.

\section{Case Study: Private Vehicle Transportation in New Zealand}

Global climate change, energy supply, and wellbeing of people and the environment are the big problems facing the world. In this section, the Strategic Analysis method is applied to 
these imperatives to develop a Motor Transportation Strategy for New Zealand. This paper gives most detail to the first step of the SA project, i.e. identifying and prioritizing the Adaptation Issues, but we also present the results of a long-running project in the AMES Lab around long range energy strategy.

\section{Identification of the Transport Fuel System and Adaptation Issues}

The current transportation fuel system for New Zealand relies nearly exclusively on imported fossil fuel oil and finished products, as characterized by Ministry of Economic Development (MED) data (MED, 2006a). Risks identified for the wellbeing of New Zealand society include commercial and residential sectors and relate to the wellbeing of the environment, both local and global. Social wellbeing is interpreted as affordable, reliable, secure, safe and sustainable access to goods and services. Environmental wellbeing is interpreted as stable resource, climate and ecological cycles. Risks that are impending or eminent in near future (10-20 years) were taken for this study. The first of the two big issues are a global peak and decline in oil supply that would result in reduced oil imports to the country. The time horizon for this risk is as short as several months, but there is a very high probability that within 5-10 years the issue will arise. The second important issue is global climate change, and financial obligations as a signatory to the Kyoto Protocol. Transportation activities represent over $50 \%$ of New Zealand's carbon emissions.

\section{Transition Concept of Low Risk Transport Fuel System}

A hypothetical low fuel risk transport system would afford the access of all members of society to goods and services without the use of imported fossil fuels. If New Zealand carried out its activities without using imported fossil fuels, the transport system would not be at risk of disrupted oil supply. If the organization of urban areas and rural activities supported primary production of food and goods without adverse impact on ecosystems, then the hypothetical system would be sustainable. The AEMS Lab has been exploring non-fossil fuel transport systems for several years (Krumdieck et al., 2004). Although they are meant to be merely part of an exercise, recently a great deal of interest has been generated by these visions of a fossil fuel free version of our familiar activity systems.

\section{Strategic Development Analysis}

The strategy to achieve a low risk transport system can be developed by proposing mitigation measures for both the near term and long term risks. The logical development path is to develop the mitigation measures and to implement them in the most cost-effective way possible. These measures may include up-taking existing technologies in the New Zealand context, adapting emerging technologies into the New Zealand system, innovation through research for the New Zealand energy system including new management and communication systems, and through changing the energy demand structure.

As mentioned previously, most of the adaptation issues can be identified and analyzed to some degree, but mitigation measures do not currently exist. The SA method represents a 
turning point in approach, from the "fossil era" thinking about solutions to problems, to a "constrained energy era" thinking, New Zealand scientists and engineers could be among the first in the world to work on developing the systems and technologies and engineering processes which allow development toward the low risk strategic target through adaptive research programs. Society will adapt to the new energy and resource constrained era, but only if it chooses to.

The results of a strategic analysis of the domestic and commercial transportation sectors are displayed in Table 1. The specific issues and the concepts identified for mitigation are further described in the following sections.

\section{Table 1. Risks to Transportation Access and Wellbeing Due to Oil Shortage}

Oil shortage defined as supply less than $85 \%$ of current use within a short time frame, e.g. 3 months.

\begin{tabular}{|c|c|c|}
\hline Risk Event & Adaptation Issue & Mitigating Concept \\
\hline \multicolumn{3}{|l|}{ Domestic Sector } \\
\hline \multirow[t]{2}{*}{$\begin{array}{l}\text { Failure of delivery-on- } \\
\text { demand supply system }\end{array}$} & $\begin{array}{l}\text { People randomly unable to } \\
\text { purchase fuel, thus loose access to } \\
\text { essential activities }\end{array}$ & $\begin{array}{l}\text { Supply distribution and allocation } \\
\text { management system }\end{array}$ \\
\hline & $\begin{array}{l}\text { Panic and uncertainty lead to anti- } \\
\text { social actions }\end{array}$ & Supply information system \\
\hline \multirow[b]{2}{*}{ Fuel Price Increase } & $\begin{array}{l}\text { Lower income people loose access } \\
\text { to activities }\end{array}$ & $\begin{array}{l}\text { Increased availability of low cost } \\
\text { public transport }\end{array}$ \\
\hline & $\begin{array}{l}\text { Increased current account deficit, } \\
\text { lowered wellbeing for low-income } \\
\text { people, reduced consumption } \\
\text { overall }\end{array}$ & $\begin{array}{l}\text { Reduced fuel consumption necessary } \\
\text { to achieve essential activities (reduce } \\
\text { fuel demand) }\end{array}$ \\
\hline $\begin{array}{l}\text { Traffic Demand } \\
\text { Growth }\end{array}$ & $\begin{array}{l}\text { Loss of access and activities due to } \\
\text { absence of low energy transport } \\
\text { options and behaviours }\end{array}$ & $\begin{array}{l}\text { Alternative shorter distance } \\
\text { destinations, trip combining, ride } \\
\text { sharing }\end{array}$ \\
\hline Fuel Demand Growth & Higher $\mathrm{CO}_{2}$ emissions & Reduced Fuel Demand \\
\hline \multicolumn{3}{|l|}{ Commercial Sector } \\
\hline \multirow[t]{2}{*}{$\begin{array}{l}\text { Failure of Product } \\
\text { Delivery }\end{array}$} & $\begin{array}{l}\text { Trade lost, products delayed or not } \\
\text { delivered, shortages of goods, } \\
\text { safety problems, reduced sanitation, } \\
\text { employment }\end{array}$ & $\begin{array}{l}\text { Low energy delivery and shipping. } \\
\text { Local production, processing and } \\
\text { market. }\end{array}$ \\
\hline & $\begin{array}{l}\text { Loss of essential and emergency } \\
\text { services }\end{array}$ & $\begin{array}{l}\text { Priority allocation system of fuel for } \\
\text { emergency, wellbeing etc }\end{array}$ \\
\hline Fuel Price Increase & $\begin{array}{l}\text { Product price increase - Inflation, } \\
\text { economic recession }\end{array}$ & $\begin{array}{l}\text { Local production of goods for local } \\
\text { markets }\end{array}$ \\
\hline
\end{tabular}




\begin{tabular}{|l|l|l|}
\hline Fuel Demand Growth & $\begin{array}{l}\text { Just-in-time shipping, road shipping } \\
\text { by trucks, and destruction of rail } \\
\text { networks }\end{array}$ & $\begin{array}{l}\text { Low energy delivery systems, local } \\
\text { production and markets of essential } \\
\text { goods }\end{array}$ \\
\hline
\end{tabular}

Descriptions of Risk Events and Issues:

1. Failure of delivery-on-demand supply system -

- Shipments of petroleum products and refinery feedstock are not available to New Zealand. The reserves in the country are depleted as demand is not managed or controlled, and fuel runs out at filling stations in random locations. This risk event is modelled on previous events, in particular the 2000 UK shortage due to fuel worker protests (BBC News 2000).

- Lack of compliance with energy savings measures (eg. speed reduction).

- Panic buying exacerbates shortage for unlucky customers. For the commercial sector, reduction in fuel supply means products do not get delivered, and commerce does not take place. Follow-on economic impacts are profound, including shortages of products for consumers and loss of employment. In the UK in 2000, even soccer matches were cancelled due to transport fuel shortages.

2. Fuel Price Increase -

- Carbon price added to the price at the pump.

- Oil production and supply shortfall causes price escalation.

- Alternative liquid fuels costly and don't fill the demand gap.

- Oil supplies mainly from the Middle East by 2010 - politically unstable.

- Oil price volatility has negative impacts on households and anti-government sentiment.

3. Traffic Demand Growth -

The risk is manifest because the transport mode, frequency, and distance profiles for New Zealand are energy intensive, e.g. urban sprawl and single mode transport systems relying on personal vehicles. As shown by Dantas et al. (2006a) energy risk to essential activities is a very strong function of urban form. If transport infrastructure investments are focused on individual mobility rather than access to goods, services and activities, then the resulting high mobility systems can become dysfunctional with even modest fuel shortfalls. Even if higher efficiency vehicles are substituted, high traffic demand growth will negate the efficiency gains, as has been the case in the USA and Europe.

For the commercial sector, a considerable growth in demand since the late 1980's has been due to a large increase in road shipping. The commercial transport system in New Zealand depends on long haul trucking.

4. Fuel Demand Growth -

If a city or a country increases fossil fuel use, then the $\mathrm{CO}_{2}$ emissions also increase. The risks associated with atmospheric $\mathrm{CO}_{2}$ pollution are not specific to transport activities, but rather are shared risks to viability of environmental resource systems. Variability in 
weather and climate has always been important risks to civilizations. Cultivation in all of its forms relies on matching local weather and climate conditions to the growing conditions of certain crops and livestock. If the weather is variable, then the risk to food production is high.

Variability in regional climate and weather has always represented a risk to transportation of goods. The commercial sector will have a higher probability of loos of ships and delay of trucks if weather patterns are unpredictable due to $\mathrm{CO}_{2}$ pollution of the atmosphere.

\section{Description of Mitigating Concepts:}

The following seven concepts were developed through standard brainstorming techniques, including borrowing from unrelated fields and role-playing. Each concept has undergone an initial analysis and feasibility assessment. All of the concepts are now subjects of research as none of them currently exist. It may be interesting to note that the mitigation concepts generated by focusing on the risks to existing systems are not among the "usual" list of remedies for future energy supply and global warming. These currently familiar R\&D topics include biofuels, enhanced oil recovery, tar sands, hybrid electric vehicles, hydrogen fuel cell vehicles and improved fuel efficiency (NREL 2007).

\section{Supply Distribution and Allocation System-}

This type of system would provide known quantities of fuel to customers so that they could plan their activities accordingly. Such a system would reduce or eliminate panic and could reduce anti-social and anti-government sentiment. The ICT-based allocation system would improve individual analysis, allowing adaptation to continue participation in activities through alternative means if it also provided advanced information about fuel availability.

\section{Supply Information System}

This type of system would provide information about supply availability and locations and timing of supplies. With this information, individuals or companies could plan their activities and transport modes accordingly to use the available fuel and not run out. Such a system would reduce or eliminate panic and could reduce anti-social and anti-government sentiment.

3. Reduced Demand for Transport and for Fuel

If activities could be carried out using less fuel, then there would be lower risk. Different societies have a proportion of activities that are accomplished using mechanized transport. Local transport systems have evolved according to local opportunities and constraints. There is currently no model, method, or theory for development and adaptation of transport systems with reduced energy and reduced transport demand.

\section{Low Energy Transport System}

The technological options for low energy consumption are well understood. For example, scooters, motorcycles and three-cylinder motor cars are low energy personal transport options. Trains consume much less fuel per tonne of cargo delivered than road trucks. 
However, a low energy urban form, urban-rural system, and national transport system is not known. In order to mitigate the impacts of a fuel shortage, non-energy options must be available at all times. This concept goes beyond current strategies for instance to make urban areas "cycle friendly" or "pedestrian safe", and aims to develop models and urban designs which are non-motor transport able.

\section{Commercial Fuel Shortages}

No mitigation factors can be conceived for fuel shortages in the commercial hauling and shipping sector that do not reduce the level of service. The mitigation concepts thus involve reduced services according to product origin, delivery time and schedule, rather than curtailing of goods movement. The first concept would be to prioritize fuel for shipping, thus increasing the fuel shortage in the personal transport sector. Another concept is a variation on the "just in time" shipping and "lowest cost product" goods sourcing systems to reflect the lowest fuel delivery and possibly the most local source.

\section{Priority Allocation System of Fuel for Essential and Emergency Services}

As with other plans for dealing with disasters, fuel allocation plans could be developed to ensure that essential goods and emergency services are not curtailed due to energy shortages. However, an allocation system that is part of the normal operation of fuel distribution and is in place before a shortage occurs would be much more effective. Once concept is a supply database and inquiry ICT system, rather like an airline reservation system, which would allow individuals and businesses to query fuel availability and schedule purchase of fuel allocated to their priority level.

\section{Local Production for Local Markets}

Food in particular could be produced locally for local markets, thus reducing transport fuel inputs. With new information networks, "nearest to market" provision of goods and services could replace "just in time" transport systems. The same technology currently used for optimized delivery time distribution networks could be adapted to lowest energy optimization.

\section{Environmental and Health Risks:}

What are the environmental risks of transport fuel shortages? This is a tricky question. From the environmental perspective, reduced consumption of fossil fuel is a MITIGATING factor for climate disruption, erosion, deforestation, urbanization, and pollution emissions.

For humans, the environmental risks of fuel shortages would include the failure of sanitation systems. Waste removal and processing (e.g. land filling) is important to health of modern urban areas. One transition concept for dealing with reduced waste transport due to fuel shortage would be an organized permitting system for packaging materials, requiring either local re-use and recycle (e.g. the milk bottle delivery) or treatment of organic wastes locally for re-use in local agriculture and production. A further concept is to direct part of the waste stream into energy production. Many of these types of systems have been developed 
for the purpose of waste management, and so could be implemented for reducing waste removal transportation requirements as well.

\subsection{Strategic scenario for transportation}

The strategic scenario focuses on solutions that would facilitate economic activities and ensure wellbeing of people and the environment by managing the use of existing fuels and developing lower energy intensity transport technologies and infrastructure. Priority number is an indication of urgency as determined by the risk analysis.

\section{Priority \#1}

- Research and development of fuel distribution and management systems for private motor transport.

- Research and development of information networks for fuel availability and public and shared transportation availability.

- Rapid deployment and up-take of these systems.

\section{Priority \#2}

- Research and development of "nearest available" low energy transport information and modelling system.

- Demonstration projects in major urban areas.

- Rapid implementation.

\section{Priority \#3}

- Research and development of modelling and engineering tools for developing current urban and urban/rural infrastructure into low energy transportation networks and urban forms.

- Local councils undertake planning exercises for low energy and negative fuel demand growth development.

- Research and development of commercial systems for local production for local markets.

- Demonstration and pilot projects in all major urban areas.

\section{Priority \#4}

Implementation of low-energy transport options, information systems, and infrastructure change through competitive bid process, construction of pilot projects, and assessment of effectiveness through research.

\subsection{Discussion and comparison with current New Zealand government strategy}

Like rest of the world, New Zealand's transport system is vulnerable to fuel shortages. Like the rest of the developed world, individuals and corporations in New Zealand are responsible for environmentally damaging emissions from fossil fuels. The Ministry of 
Economic Development (MED, now called MBIE) generates economics-based scenarios of future energy demand. Recently, a discussion paper, "Options for Government Response to an Oil Supply Disruption" has been released for public comment (MED 2006b). This newest document deals with the measures to respond to an emergency oil supply disruption. These measures fall into two categories:

Measures to Improve Supply -

- Release stocks form NZ petroleum reserve to the market

- Domestic production increased

- Petroleum product specifications relaxed

Measures to Restrain Demand -

- Appeals made to the public via public information campaign to voluntarily save fuel

- Government compulsion used to restrain demand, prevent hoarding and distribute a limited amount of fuel - no methods specified

- Substitute alternative fuels (non-specific)

There is a marked difference between the BAU-driven economic scenario approach used by the New Zealand government and the risk management approach of the strategic analysis scenario. In particular, the strategic analysis method produces a list of immediate projects and directions for research with specific desired outcomes. It only suggests a particular mitigation measure if it is currently known to be feasible. This is a major issue for ideas such as substituting alternative fuels. According to the MED report, "Energy Outlook 2030", the transportation system in 2030 would be at even greater risk than the current system. (MED, 2006c). Three scenarios were considered by MED and summarized below:

\section{$\underline{\text { Business as Usual Case }}$}

"Oil remains the largest energy source for New Zealand, and its supply grows by about $35 \%$ between 2005 and 2030. Rising oil use reflects increasing transport demand, especially road transport. The bulk of this oil will be imported, as it is now."

"National transport is the sector with the largest energy demand and the largest growth in absolute terms. It grows by about $35 \%$. Road transport accounts for about $75 \%$ of the growth in national transport."

\section{High GDP Growth Case}

"Overall energy use is about $7.5 \%$ higher by 2030 than it would be in the Base Case. The results show that coal, oil, and gas would be the major sources of this additional energy. Not surprisingly, given that there are no real alternatives under 'business as usual' assumptions, oil absorbs the growth in transport demand."

\section{Low GDP Growth Case}

"Overall energy demand in the Low GDP Growth Case is about 6\% lower in 2030 than in the Base Case." 
The MED scenarios all depict significant increase in oil imports for New Zealand over the next twenty years. This long range target is vastly different from the zero fossil import transformation concept discussed above from the Strategic Analysis project. Neither the MED scenarios nor the SA concept are actual "predictions". Nor are they meant to represent desired or obtainable targets. However, they do highlight the vastly different thinking between the approaches of economic projection used by MED and risk analysis and mitigation employed in the SA project.

There is no evidence that energy sustainability in New Zealand can simply be purchased through technology from overseas. The salient case for relevant research into the novel ICT systems necessary to manage constrained energy supplies is that neither the fundamental understanding nor any enabling technologies currently exits. Research funding must be targeted at enabling technologies to address New Zealand's most critical issues.

\section{Conclusion and future work}

The strategic analysis method has been proposed, but is in the early stages of applications research. Continuing research in this group is giving high priority to development of risk mitigation measures and the strategic development capability. For example, we are working on a fuel supply management system which could be implemented before a fuel supply disruption and used to manage demand response in a rational manner. A project recently completed has developed an analysis method and software implementation package for analysis of energy risk to essential transportation activities as related to urban form (Saunders at el. 2006; Dantas at el. 2006b; Dantas at el 2006c). We are also working on renewable energy transportation technologies and on modelling of fossil fuel free urban forms and urban/rural integration. Finally, we are working on ways to measure adaptive capacity of urban areas and adaptation technologies and information systems that can help people adjust their fuel consumption and make choices about low fuel use destinations, and that can organize shipping activities for minimum fuel consumption. This type of work, to reduce the unsustainable energy use and manage the issues of adaptive change is an emerging field called Transition Engineering.

\section{References}

1. Bassi, A. Modelling U.S. Energy with Threshold 21 (T21). Proceedings of the 24th International System Dynamics Conference (ISDC), Nijmegen, 23-27 July 2006.

2. Bureau of Infrastructure, Transport and Regional Economics (BITRE), 2009, Transport energy futures: long-term oil supply trends and projections, Report 117, Canberra ACT.

3. Canyurt, O. and Ozturk, H. Three different applications of genetic algorithm (GA) search techniques on oil demand estimation. Energy Conversion and Management 47 (2006) 3138-3148. 
4. Dantas, A., Krumdieck, S., Saunders, M., Assessing the risk to suburban activities associated with transport energy availability as a function of urban form, Transportation Research Board 85 ${ }^{\text {th }}$ Annual Meeting (Washington D.C. January 22-26, 2006) CD-ROM.

5. Dantas, A., Krumdieck, S., Page, S., Energy Risk to Activity Systems as a Function of Urban Form, Land Transport New Zealand Research Report, 2006.

6. Energy Shift Project, Science for Energy Scenarios (Les Houches, France February 2-7, 2014). http://www.science-and-energy.org

7. IEA, World Energy Outlook (2013). www.iea.org

8. Krumdieck, S., "Chapter 13. Transition Engineering”, In: Principles of Sustainable Energy, $2^{\text {nd }}$ Edition, Ed: F. Kreith and S. Krumdieck, CRC Press, Taylor \& Francis Group, (2014) p.698-728.

9. Krumdieck, S., Transition Engineering: adaptation of complex systems for survival, International Journal of Sustainable Development, Vol. 16, No. 3/4, (2013) 310-321.

10. Krumdieck, S., S. Page, A. Dantas, Urban form and long term fuel supply decline: A method to investigate the peak oil risks to essential activities, Transportation Research Part A: 44 (2010) 306-322.

11. Krumdieck, S. and A. Hamm, Strategic analysis methodology for energy systems with remote island case study, Energy Policy, Vol 37,9 (2009) 3301-3313.

12. Krumdieck, S., Hamm, A., Dantas. A., and Minges, S., Performance-Objective Design for a Renewable Energy Transportation Circuit of Christchurch, New Zealand, in Proceedings of the World Renewable Energy Congress VIII (Denver, Colorado, 29 Aug3 Sept 2004).

13. Meadows, D., Randers, J. and Meadows, D., Limits to Growth, The 30-Years Update, May 2004.

14. Ministry of Economic Development, Govt. of New Zealand, 2006, www.med.govt.nz

15. Ministry of Economic Development, Govt. of New Zealand, Discussion Paper: Options for Government Response to an Oil Supply Disruption, Sept 2006, www.med.govt.nz

16. Ministry of Economic Development, Govt. of New Zealand, Energy Outlook 2030, 2006, www.med.govt.nz

17. Moffatt, I., Hierarchical, dynamic modelling and sustainable development. Handbook of Sustainable Development Planning, Studies in Modelling and Decision Support, 2004, Edward Elgar Publishing Limited.

18. National Renewable Energy Laboratory, Advanced Vehicles and Fuels Research, January 2007, www.nrel.gov/vehiclesandfuels

19. Pickton, D. and Wright. S., What's SWOT in strategic analysis? Strategic Change 7, 101109 (1998).

20. Pohekar, S.D., Ramchandran, M., Application of multi decision making to sustainable energy planning- A review. Renewable and Sustainable Energy Reviews 8 (2004) 365381. 
21. Saunders, M. J., Krumdieck, S., Dantas, A., Energy reliance, urban form and the associated risk to urban activities, Road \& Transport Research, Vol 15 No 1 (2006) 2943.

22. Terrados, J., Almonacid, G., and Hontoria, L., Regional energy planning through SWOT analysis and strategic planning tools. Impact on renewable development. Renewable and Sustainable Energy Reviews, Vol. 11 (6) (2007) 1275-1287.

23. Tisdell, C., Sustainability: can it be achieved? Is economics the bottom line?, Handbook of Sustainable Development Planning, Studies in Modelling and Decision Support, Edward Elgar Publishing Limited, (2004).

24. United Nations. Our Common Future, report from the World Commission on Environment and Development. Oxford: Oxford University Press; 1987

25. Yamaguchi, K. Modelling long-term sustainability, Handbook of Sustainable Development Planning, Studies in Modelling and Decision Support, Edward Elgar Publishing Limited (2004).

(C) 2014 by the authors; licensee MDPI, Basel, Switzerland. This article is an open access article distributed under the terms and conditions of the Creative Commons Attribution license (http://creativecommons.org/licenses/by/3.0/). 